\title{
Biliary sludge: A risk factor for 'idiopathic' pancreatitis?
}

\author{
PAUl J MAROTTA MD, James C GREGOR MD, DONALD H TAVES MD
}

\begin{abstract}
PJ MarotTa, JC Gregor, DH TAves. Biliary sludge: A risk factor for 'idiopathic' pancreatitis? Can J Gastroenterol 1996; $10(6): 385-388$. Idiopathic acute pancreatitis is common. Recent evidence suggests that biliary sludge may be the etiology in many patients with this disorder. In this case-control study, admission ultrasound examinations of patients with idiopathic pancreatitis, patients with acute alcohol-associated pancreatitis and a control group were compared. Biliary sludge was found in seven of 21 patients $(33 \%)$ with idiopathic pancreatitis, two of $25(8 \%)$ with acute alcohol-associated pancreatitis and one of 63 controls (1.6\%). Comparison of idiopathic pancreatitis patients with both acute alcohol-associated pancreatitis patients and controls for the presence of sludge revealed odds ratios of 31.0 (95\% CI 3.5 to 273) and 5.8 (95\% CI 1.1 to 32.0), respectively. Also observed was a trend towards higher levels of liver enzymes, bilirubin and amylase in patients with idiopathic pancreatitis who had sludge identified. This study provides further evidence linking biliary sludge with a significant proportion of patients with idiopathic acute pancreatitis.
\end{abstract}

Key Words: Alcohol, Bile, Cholelithiasis, Etiology, Idiopathic pancreatitis, Pancreatitis, Sludge

\section{Boue biliaire : facteur de risque de pancréatite idiopathique?}

RÉSUMÉ : La pancréatite aiguë idiopathique est fréquente. Selon de récentes preuves, la boue biliaire pourrait en être l'étiologie chez de nombreux patients atteints de cette maladie. Dans cette étude cas/témoins, des examens échographiques à l'admission de patients souffrant de pancréatite idiopathique, de patients souffrant de pancréatite aiguë d'origine alcoolique et d'un groupe témoin ont été comparés. La boue biliaire s'est révélée présente chez 7 patients sur 21 (33\%) souffrant de pancréatite idiopathique, chez 2 patients sur $25(8 \%)$ souffrant de pancréatite aiguë d'origine alcoolique et chez 1 des 63 témoins $(1,6 \%)$. La comparaison des patients atteints de pancréatite idiopathique et des patients souffrant de pancréatite aiguë d'origine alcoolique et des témoins pour ce qui est de la présence de boue biliaire révélait un risque relatif de 31,0 (95\% IC, 3,5 à 273) et de 5,8 (95\% IC, $1,1$ à 32,0$)$ respectivement. Une tendance à des taux plus élevés d'enzymes hépatiques, de bilirubine et d'amylase chez les patients souffrant de pancréatite idiopathique et présentant de la boue biliaire a également été observée. Cette étude fournit d'autres preuves établissant un lien entre la boue biliaire et une proportion significative de patients atteints de pancréatite idiopathique aiguë.
A cute pancreatitis is characterized clinically by the sudden onset of abdominal pain associated with elevations in blood or urinary amylase. Functional restitution occurs if the primary cause and complications are eliminated (1). Numerous etiologies have been suggested $(2,3)$; however, in general, $60 \%$ to $80 \%$ of episodes are related to biliary tract stones or ethanol abuse (4). Despite intensive investigation, $9 \%$ to $39 \%$ of episodes do not have an attributable cause and are classified as idiopathic (5). Recent reports suggested that a large number of these cases, perhaps a majority, are associated with biliary sludge detectable by either ultrasound or microscopic bile analysis (5-8). Grossly, sludge appears as a sandy precipitate. It comprises thickened gallbladder mucoprotein with tiny entrapped cholesterol crystals or calcium bilirubinate granules $(9,10)$. It has also been suggested that interventions such as cholecystectomy, endoscopic sphincterotomy or crystal dissolution with ursodeoxycholic acid may reduce the rate of recurrent pancreatitis $(6,7)$.

The purpose of our study was to determine the prevalence of idiopathic pancreatitis at our institution and to determine whether there is a correlation between idiopathic pancreatitis and gallbladder sludge. 
TABLE 1

Etiologies of pancreatitis

\begin{tabular}{lcc}
\hline Etiology & Patients & Cases \\
\hline Idiopathic & $32(35 \%)$ & $39(32 \%)$ \\
Alcohol-associated & $32(35 \%)$ & $51(42 \%)$ \\
Gallstone-associated & $19(21 \%)$ & $21(17 \%)$ \\
Post-ERCP & $5(5 \%)$ & $5(4 \%)$ \\
Drug-induced & $3(3 \%)$ & $4(3 \%)$ \\
Tumour & $1(1 \%)$ & $1(1 \%)$ \\
Total & 92 & 121 \\
\hline
\end{tabular}

Percentages may not add to 100 due to rounding. ERCP Endoscopic retrograde cholangiography

\section{MATERIALS AND METHODS}

Charts of all patients with a final discharge diagnosis of pancreatitis admitted to St Joseph's Health Centre, London, Ontario between January 1989 and February 1992 were reviewed. This health centre provides primary care to local residents and functions as a referral centre for the surrounding area.

Ninety-two patients were found to have acute pancreatitis as defined by an episode of acute abdominal pain accompanied by an elevated serum amylase (greater than $100 \mathrm{U} / \mathrm{L}$ ). Etiological factors were determined from the available history and ultrasonic studies. Gallstone-associated pancreatitis was defined as cholelithiasis on presenting abdominal ultrasound or choledocholithiasis as demonstrated by ultrasound or endoscopic retrograde cholangiography (ERCP). Alcohol-associated pancreatitis was defined as the absence of gallstones on admission abdominal ultrasound and the patient's consumption of more than $60 \mathrm{~g}$ of ethanol in the $48 \mathrm{~h}$ preceding symptom onset. Pancreatitis was deemed idiopathic if the above criteria (ie, the criteria for gallstone- and alcohol-associated pancreatitis) were not present and if there was no evidence of hypercalcemia, hypertryglyceridemia or recent initiation of therapy with a medication known or presumed to induce pancreatitis.

Ultrasound examinations within $24 \mathrm{~h}$ of the first admission during the study period were considered for review. Patients were excluded if they had a previous cholecystectomy or the ultrasound was unavailable. Also reviewed were abdominal ultrasound examinations of control patients, who were without acute abdominal pain or a history of hepatobiliary disease or previous cholecystectomy, and were age- and sex-matched to the idiopathic group. Controls were selected from patients receiving abdominal ultrasound examinations performed between January 1992 and March 1992 for indications including chronic abdominal pain, search for malignancy, renal disease and abdominal aortic aneurysm surveillance. Three controls of the same sex and within five years of age were selected for each patient with idiopathic pancreatitis who was eligible for the study.

A standardized technique for examining the biliary system was followed in all patients. After an overnight fast, scanning imaged the gallbladder in its entirety from neck to fundus and in longitudinal and transverse planes with the patient in the supine and left posterior oblique positions. Biliary sludge was defined as a fluid-fluid interface in the dependant portion of the gallbladder with characteristic low amplitude echoes without acoustic shadowing (6).

A blinded, experienced radiologist randomly reviewed all abdominal ultrasounds, looking specifically for gallstones, biliary sludge or dilation of the intra- or extra-hepatic biliary tree.

The proportion of patients with sludge was calculated for the idiopathic group, alcohol group and the controls. Odds ratios and confidence intervals were derived using the method described by Morris and Gardner (11). Mean laboratory values for patients with and without sludge were compared using a two sample $t$ test.

\section{RESULTS}

The various etiologies are listed in Table 1 . The most common causes of acute pancreatitis were alcohol-associated and idiopathic; 32 patients (35\%) were in each of those groups. Alcohol-associated pancreatitis was responsible for more admissions than idiopathic pancreatitis $(42 \%$ versus $32 \%)$ because of a larger number of recurrent episodes. Nineteen patients $(21 \%)$ had gallstone-associated disease. Three of the 19 also had sludge present and were entered into the gallstone group. Five patients (5\%) had pancreatitis occurring post-ERCP and one patient (1\%) had an associated adenocarcinoma of the pancreas. Drug therapy initiation (pentamidine, dideoxyinosine, 6-mercaptopurine) was associated with pancreatitis in three patients $(3 \%)$. Six patients were taking thiazide diuretics and three patients were taking

\section{TABLE 2}

\section{Patient characteristics for each of the three major etiologies}

\begin{tabular}{lccc}
\hline & Idiopathic $(\mathbf{n}=\mathbf{3 2})$ & Alcohol $(\mathbf{n}=\mathbf{3 2})$ & Gallstone $(\mathbf{n}=\mathbf{1 9})$ \\
\hline Age in years (range) & $59(32-92)$ & $40(20-59)$ & $59(23-89)$ \\
Sex (male:female) & $10: 22$ & $25: 7$ & $6: 13$ \\
Amylase (normal $20-100 \mathrm{U} / \mathrm{L})$ & $1603(163-5600)$ & $820(112-7180)$ & $2197(146-4690)$ \\
Aspartate aminotransferase $(\mathrm{normal}<30 \mathrm{U} / \mathrm{L})$ & $90(12-588)$ & $100(16-565)$ & $181(52-361)$ \\
Alanine aminotransferase $(\mathrm{normal}<30 \mathrm{U} / \mathrm{L})$ & $80(7-507)$ & $77(10-358)$ & $191(29-590)$ \\
Alkaline phosphatase $($ normal $25-120 \mathrm{U} / \mathrm{L})$ & $120(51-249)$ & $102(40-239)$ & $188(67-462)$ \\
$\gamma$-glutamyltransferase $($ normal $<50 \mathrm{U} / \mathrm{L})$ & $102(10-575)$ & $201(22-919)$ & $253(38-616)$ \\
Bilirubin $($ normal 3-17 $\mu \mathrm{mol} / \mathrm{L})$ & $21(5-61)$ & $22(6-75)$ & $41(8-153)$ \\
Abnormal common bile duct $(>7 \mathrm{~mm})$ & $1 / 21$ & $0 / 25$ & $6 / 19$ \\
\hline
\end{tabular}


estrogen therapy; because these medications did not appear to be causally related to the pancreatitis those patients were included in our study.

Patient characteristics for the three most common etiologies are shown in Table 2.

Female predominance and older age were features of both idiopathic and gallstone-associated pancreatitis. Comparable with results in previous studies (7), patients with gallstone-associated pancreatitis had higher amylase values, although there was considerable overlap among groups. This patient group also tended to have more marked elevation of liver enzymes and bilirubin. Abdominal ultrasound examinations revealed the common bile duct to be dilated (more than $7 \mathrm{~mm}$ ) in six patients (32\%) in the gallstone-associated group, whereas there was no duct dilation in any patient in the alcohol-associated group. One patient in the idiopathic group with minimal dilation of the common bile duct $(7.5 \mathrm{~mm})$ subsequently had a normal ERCP. Seven other patients in the idiopathic group underwent ERCP. The common bile duct was successfully visualized in six (all were normal). Bile aspiration and examination was not performed.

Five patients were originally reported to have sludge; upon review of the original abdominal ultrasounds, however, the number increased to 10 patients.

The idiopathic group was compared with both the alcohol-associated and the control group for the presence of gallbladder sludge (Figure 1). Eleven of the 32 idiopathic patients were excluded (seven had a previous cholecystectomy and four did not have an ultrasound performed within $24 \mathrm{~h}$ of admission). Of the 32 alcohol-associated patients, seven were excluded (six had a previous cholecystectomy and one did not have an appropriate ultrasound). Sludge was demonstrated by abdominal ultrasound in seven of 21 patients (33\%) with idiopathic pancreatitis versus two of 25 patients $(8 \%)$ with alcohol-associated pancreatitis to yield an odds ratio of 5.8 (95\% CI 1.1 to 32.0). One patient in the control group $(n=63)$ showed ultrasound evidence of sludge, giving an odds ratio of 31.0 (95\% CI 3.5 to 273) compared with the idiopathic group.

The amylase and liver profiles of patients with idiopathic pancreatitis according to the presence of sludge were compared (Table 3). There was a trend towards higher values in patients in whom sludge was detected.

Patient follow-up was through hospital records and telephone interviews with the patients and their primary care physician. Information was obtained on 17 of 21 patients with idiopathic pancreatitis, including all seven with sludge. There were four confirmed relapses of acute pancreatitis, two occurring in the sludge subgroup.

Follow-up was obtained on all 10 patients with biliary sludge (seven with idiopathic pancreatitis, two with alcoholassociated and one control). Six of the 10 (four with idiopathic pancreatitis, one with alcohol-associated and one control) remained asymptomatic at a mean follow-up of 43 months and did not require repeat abdominal ultrasound. Four patients had recurrent symptoms. Two of the four (both with idiopathic pancreatitis) had relapses of pancreatitis,

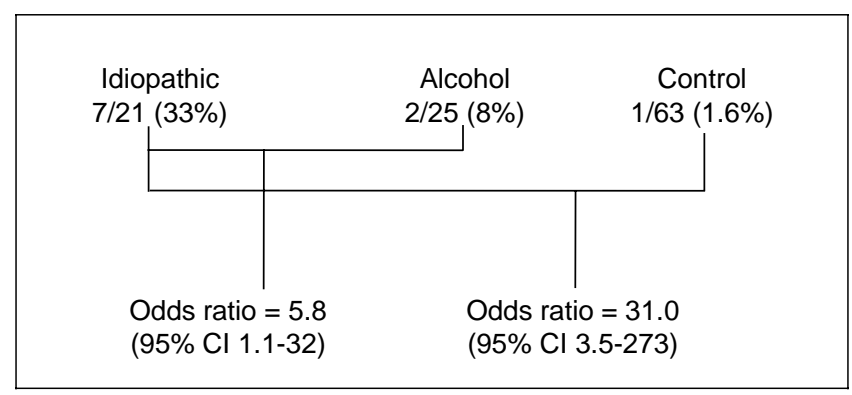

Figure 1) Proportion of patients in whom sludge was identified

\section{TABLE 3}

Characteristics of patients with idiopathic pancreatitis

\begin{tabular}{lcc}
\hline & $\begin{array}{c}\text { Sludge } \\
\text { detected }(\mathbf{n}=7)\end{array}$ & $\begin{array}{c}\text { Sludge not } \\
\text { detected }(\mathbf{n}=14)\end{array}$ \\
\hline Amylase (normal 20-100 U/L)* & $1726(644-2724)$ & $914(51-2862)$ \\
AST (normal <30 U/L) & $133(13-404)$ & $84(13-588)$ \\
ALT (normal <30 U/L) & $109(13-320)$ & $72(7-507)$ \\
ALP (normal 25-120 U/L) & $118(79-210)$ & $106(58-186)$ \\
$\gamma$-GT (normal <50 U/L) & $116(11-350)$ & $68(10-294)$ \\
Bilirubin (normal 3-17 $\mu \mathrm{mol} / \mathrm{L})$ & $26(13-61)$ & $18(5-45)$ \\
\hline
\end{tabular}

${ }^{*} P=0.03$ (all other comparisons were not significant at $P>0.05$ ). ALP Alkaline phosphatase; ALT Alanine aminotransferase; AST Aspartate aminotransferase; GT Glutamyltransferase

and repeat ultrasound showed persistent sludge in one patient and the presence of gallstones in the other. The remaining patient with idiopathic pancreatitis had biliary pain; repeat ultrasound revealed gallstones. He underwent cholecystectomy and was asymptomatic at follow-up four years later. The one alcohol-associated pancreatitis patient with sludge at initial presentation had recurrent abdominal pain three months later. Abdominal ultrasound at that time was negative for stones and sludge.

Follow-up could only be obtained in 10 of 14 patients with sludge-negative idiopathic pancreatitis. Two patients had confirmed relapses, again with no ultrasonographic evidence of biliary sludge. A third patient subsequently developed gallstones. The remaining seven patients remained asymptomatic at a mean follow-up of 41 months and did not require repeat ultrasound.

\section{DISCUSSION}

Using a retrospective analysis we classified acute pancreatitis as idiopathic in more than one-third of 92 consecutive patients seen at our institution. This figure may be somewhat higher than results from most studies because we were conservative in attributing some cases to commonly used medications. Even if a more liberal definition had been used, idiopathic pancreatitis still made up a substantial proportion of our patients.

We felt that abdominal ultrasound assessment alone for detecting biliary sludge was reasonable for a number of reasons. It is inexpensive, noninvasive and routinely done in the work-up of pancreatitis of any etiology. It is also performed shortly after the onset of symptoms, versus biliary or stimu- 
lated duodenal aspiration which generally is performed several weeks later. The presence of sludge near the time of symptom onset argues against pancreatitis precipitating sludge in the biliary system. Microscopic examination is more sensitive than ultrasound examination in detecting the presence of biliary sludge (6); hence, we have underestimated its prevalence. Microscopic examination of duodenal fluid or direct common bile duct cannulation is necessary in patients who have had a previous cholecystectomy and present with idiopathic pancreatitis.

This study provides support for the association of biliary sludge with idiopathic pancreatitis. Sludge is more commonly seen in idiopathic pancreatitis than in alcohol-associated disease. This comparison controls, to some degree, for confounders such as fasting and pancreatitis and thus strengthens the case for causation.

There was also a trend towards higher amylase and liver biochemical abnormalities in patients with sludge-associated idiopathic pancreatitis, approaching the levels found in gallstone pancreatitis, which is similar to findings by Ros et al (7) and could be evidence that sludge causes pancreatitis by a mechanism similar to that causing gallstone pancreatitis.

Our definition of idiopathic pancreatitis did not include ERCP as a prerequisite. If further evidence supports biliary sludge as the main cause of idiopathic pancreatitis then both common duct cholangiography and biliary aspirate (by

\section{REFERENCES}

1. Singer MV, Gyr K, Sarles H. Revised classification of pancreatitis: Report of the Second International Symposium on the classification of pancreatitis in Marseille, France, March 28-30, 1984.

Gastroenterology 1985;89:683-90.

2. Marshall JB. Acute pancreatitis - a review with an emphasis on new developments. Arch Intern Med 1993;153:1185-98.

3. Steinberg W, Tenner S. Acute pancreatitis. N Engl J Med 1994;330:1198-210.

4. Steer ML. Acute pancreatitis. In: Yamada T, Alpers D, eds. Textbook of Gastroenterology, vol 2. Philadelphia: JP Lippincott, 1991:1859-74

5. Neoptolemos JP, Davidson BR, Winder AF, Vallance D. Role of duodenal bile crystal analysis in the investigation of 'idiopathic' pancreatitis. Br J Surg 1988;75:450-3.

6. Lee SP, Nicholls JF, Park HZ. Biliary sludge as a cause of acute pancreatitis. N Engl J Med 1992;326:589-93.
ERCP) would be necessary to define a case of true idiopathic pancreatitis. Our study does not address the practical question of patient management. Because sludge was detected by the initial reporting radiologist in only $50 \%$ of patients with it, one should look specifically for its presence on admission abdominal ultrasound. Also, two of the 10 patients with sludge developed symptomatic gallstones. Ros and co-workers (7) showed a high rate of eventual gallstone formation in patients with sludge, and, hence, a case could be made for serial abdominal ultrasound examinations, at least over the first year.

The most important issue in treating pancreatitis is prevention of recurrent episodes. The two- to three-year recurrence rate has been estimated at approximately 30\% (12) but may be as high as $70 \%$ in patients who have sludge (6). Two prospective studies $(6,7)$ were able to reduce this rate substantially in a nonrandomized subset of patients.

Further evidence of a causative role for biliary sludge and delineation of a practical management strategy requires more prospective study. Following evaluation for the presence of sludge, we suggest that patients with acute idiopathic pancreatitis be randomized to cholecystectomy, endoscopic sphincterotomy, and medical dissolution or observation, and subsequently be followed to determine whether intervention affects the recurrence rate of pancreatitis and its associated morbidity and mortality.

7. Ros E, Navarro S, Bru C, Garcia-Pugés A, Valderrama R. Occult microlithiasis in 'idiopathic' acute pancreatitis: Prevention of relapses by cholecystectomy or ursodeoxycholic acid therapy. Gastroenterology 1991;101:1701-9.

8. Paricio PP, Olmo DG, Franco EP, González AP, González LC, López JB. Gallbladder cholesterolosis: an aetiological factor in acute pancreatitis of uncertain origin. Br J Surg 1990;77:735-6.

9. Johnston DE, Kaplan MM. Pathogenesis and treatment of gallstones. N Engl J Med 1993;328:412-21.

10. Lee SP. Pathogenesis of biliary sludge. Hepatology 1990;12:200-5.

11. Morris JA, Gardner MJ. Calculating confidence intervals for relative risks, odds ratios, and standardised ratios and rates. BMJ 1988;296:1313-6.

12. Trapnell JE, Duncan EHL. Patterns of incidence in acute pancreatitis. BMJ 1975;ii:179-83. 


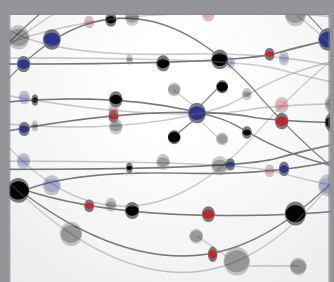

The Scientific World Journal
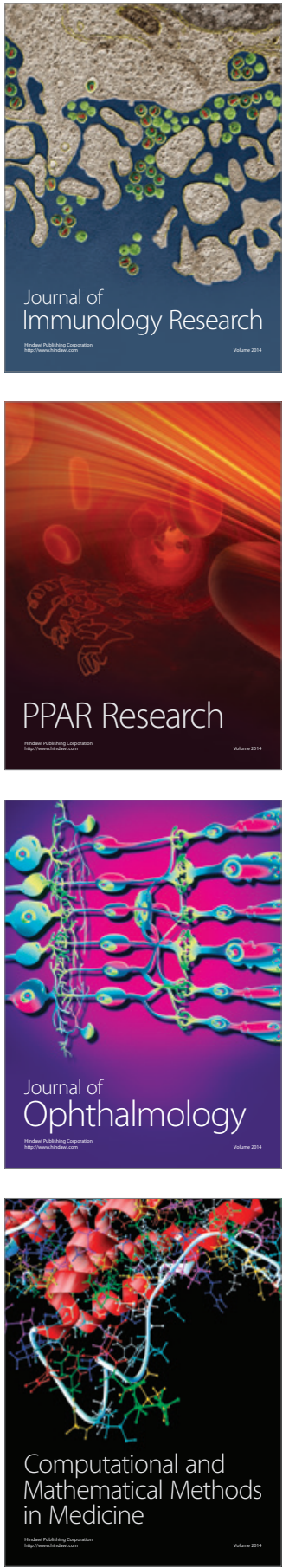

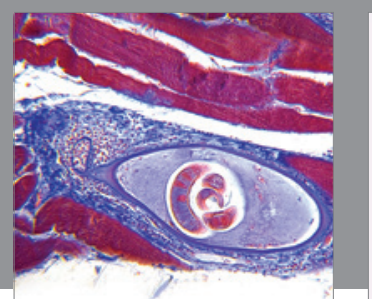

Gastroenterology Research and Practice

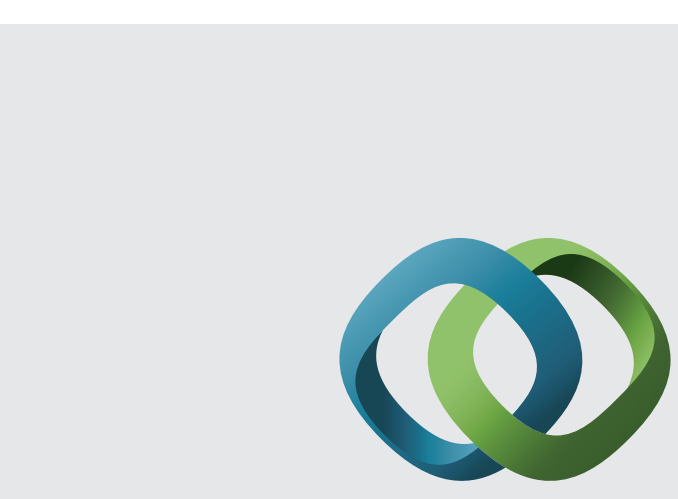

\section{Hindawi}

Submit your manuscripts at

http://www.hindawi.com
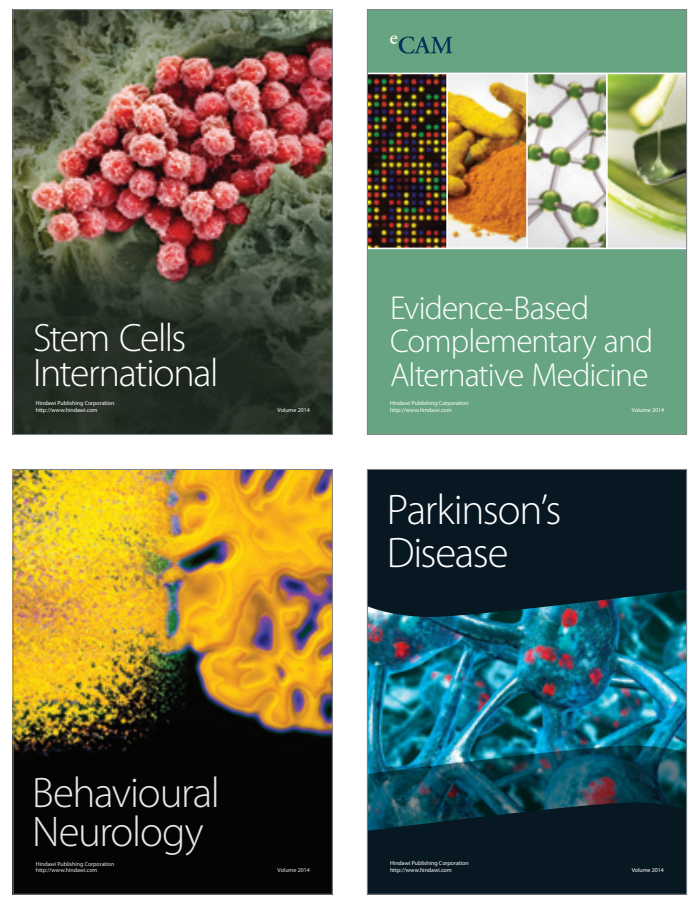
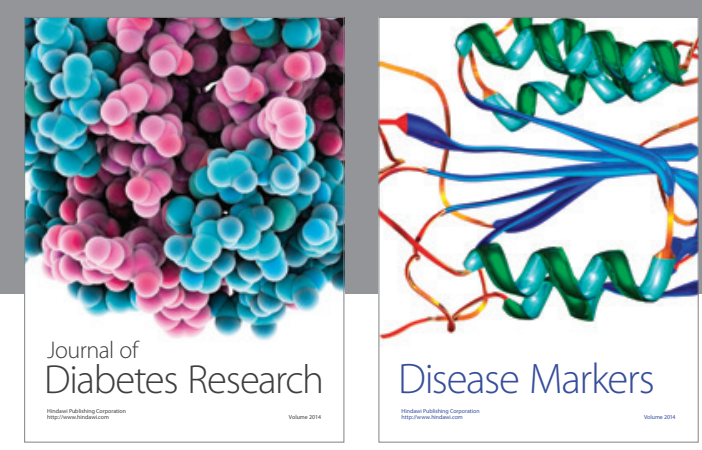

Disease Markers
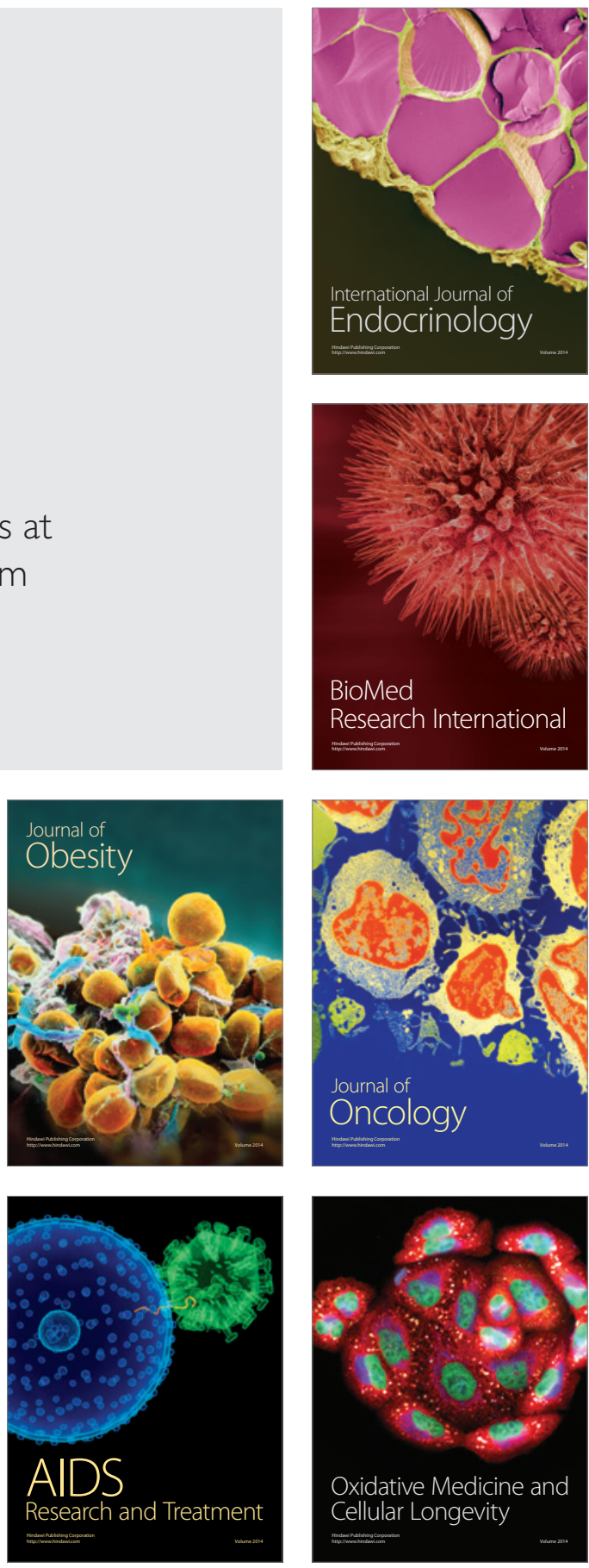